\title{
Correspondence
}

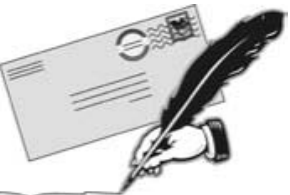

\section{Vision loss after spine surgery: a new bypothesis}

To the Editor:

As new reports concerning vision loss after spine surgery continue to be published, ${ }^{1,2}$ it is crucial to explore possible mechanisms. The incidence of vision loss after noncardiac surgery is $0.0008 \%,{ }^{3}$ while it is $0.2 \%$ following spine surgery, ${ }^{4}$ with the causes usually taken to be anemia or hypotension. ${ }^{5}$ We hypothesize a possible additional mechanism: that the use of large amounts of crystalloids in such cases can lead to an accumulation of edema in the eye socket with the production of an "eye compartment syndrome". Presumably, increased eye socket pressure in this setting can lead to ischemia of the optic nerve, especially in the posterior segment having a single blood supply derived from the ophthalmic artery. ${ }^{6,7}$

Our hypothesis is supported by the frequent observation of facial edema and chemosis in long spine cases carried out in the prone position, as well as by occasional cases of blindness after bilateral neck dissection where the internal jugular veins have been sacrificed. ${ }^{8}$ Here, the loss of vision is attributed to back pressure from the distended ophthalmic veins, leading to ischemic neuropathy.

Experience suggests that prone positioning for spine surgery may play a particularly important role. We recommend that, where possible, prone patients should be positioned so that their heads are higher than the heart, and that any position that might impair venous drainage of the head be avoided. In addition, anything that might lead to direct pressure on the orbit must be carefully prevented.

We believe that eye compartment syndrome as a cause of blindness should be considered in any prone spine case managed with extensive use of crystalloids and where anemia and hypotension have been excluded. We also speculate that the use of colloids for spine cases in the prone position may offer the potential to reduce eye socket edema and subsequent vision loss.

Ehab Farag MD FRCA

D. John Doyle MD PhD FRCPC

Cleveland Clinic Foundation, Cleveland, USA

E-mail: doylej@ccf.org

Accepted for publication November 26, 2005.

\section{References}

1 Kamming D, Clarke S. Postoperative visual loss following prone spinal surgery. Br J Anaesth 2005; 95 : 257-60.

2 American Society of Anesthesiologists Task Force on Perioperative Blindness. Practice Advisory for Perioperative Visual Loss Associated with Spine Surgery. Accessed November 16, 2005. Available from URL; http://www.asahq.org/publicationsAndServices/BlindnessAdvisoryFinal.pdf.

3 Warner ME, Warner MA, Garrity JA, MacKenzie RA, Warner DO. The frequency of perioperative vision loss. Anesth Analg 2001; 93: 1417-21.

4 Stevens WR, Glazer PA, Kelley SD, Lietman TM, Bradford DS. Ophthalmic complications after spinal surgery. Spine 1997; 22: 1319-24.

5 Brown RH, Schauble JF, Miller NR. Anemia and hypotension as contributors to perioperative loss of vision. Anesthesiology 1994; 80: 222-6.

6 Dunker S, Hsu HY, Sebag J, Sadun AA. Perioperative risk factors for posterior ischemic optic neuropathy. J Am Coll Surg 2002; 194: 705-10.

7 Asensio JA, Forno W, Castillo GA, Gambaro E, Petrone $P$. Posterior ischemic optic neuropathy related to profound shock after penetrating thoracoabdominal trauma. South Med J 2002; 95: 1053-7.

8 Worrell L, Rowe M, Petti G. Amaurosis: a complication of bilateral radical neck dissection. Am J Otolaryngol 2002; 23: 56-9.

\section{Objective techniques for identification of the epidural space in infants and children}

To the Editor:

I read with interest the results of a survey of Canadian pediatric anesthesiologists regarding identification of the epidural space in infants and children. ${ }^{1}$ However, I was somewhat disappointed to learn that the iv micro-drip infusion set technique for identification of the space ${ }^{2}$ is not being practiced in Canada. This technique enables the operator to hold the epidural needle with two hands, thus providing more precise control of the needle, and identify the epidural space by an objective sign, either free flow of fluid from the drip 